\title{
Alexandre Tarrête, Les héros stoïciens, des martyrs païens? Quelques relectures de la philosophie du Portique à la fin du XVI siècle
}

\section{Filippo Fonio}

\section{(2) OpenEdition \\ 1 Journals}

\section{Edizione digitale}

URL: https://journals.openedition.org/studifrancesi/40537

DOI: $10.4000 /$ studifrancesi.40537

ISSN: 2421-5856

\section{Editore}

Rosenberg \& Sellier

\section{Edizione cartacea}

Data di pubblicazione: 1 juillet 2004

Paginazione: 176-177

ISSN: 0039-2944

\section{Notizia bibliografica digitale}

Filippo Fonio, «Alexandre Tarrête, Les héros stoïciens, des martyrs païens? Quelques relectures de la philosophie du Portique à la fin du XVIe siècle», Studi Francesi [Online], 142 (XLVIII | I) | 2004, online dal 30 novembre 2015, consultato il 09 septembre 2021. URL: http://journals.openedition.org/studifrancesi/ 40537 ; DOI: https://doi.org/10.4000/studifrancesi.40537

Questo documento è stato generato automaticamente il 9 septembre 2021.

\section{cc) $(8)$}

Studi Francesi è distribuita con Licenza Creative Commons Attribuzione - Non commerciale - Non opere derivate 4.0 Internazionale. 


\title{
Alexandre Tarrête, Les héros stoïciens, des martyrs paiens? Quelques relectures de la philosophie du Portique à la fin du XVI siècle
}

\author{
Filippo Fonio
}

\section{NOTIZIA}

ALEXANDRE TARRÊTE, Les héros stoïciens, des martyrs païens? Quelques relectures de la philosophie du Portique à la fin du XVI e siècle, in FRANK LESTRINGANT, PIERRE-FRANÇOIS MOREAU, Martyrs et martyrologes, «Revue des Sciences Humaines», 269, I, 2003, pp. 87-110.

Il saggio in questione illustra le posizioni di alcuni intellettuali neo-stoici o stoicheggianti degli ultimi decenni del XVI sec. in riferimento al martirio, in particolare in merito a come collocare sull'asse delle virtù cristiane le grandi figure di personaggi uccisi, o uccisisi in conformità a dettami stoici. Mentre infatti il XVII sec. vedrà lo sviluppo di un anti-stoicismo cristiano, diversi autori tardo-cinquecenteschi, tra cui Juste Lipse, Guillaume du Vair, Théodore-Agrippa d'Aubigné, Montaigne, mantengono un atteggiamento oscillante tra l'ammirazione nei confronti di questi eroi pagani e della loro virtù, sentimento che li porta a narrarne le circostanze della morte a titolo di exempla, e la condanna del loro gesto, specie nel caso in cui essi si siano tolti la vita. Emblematico a tal proposito è il caso di d'Aubigné, al quale lo studioso dedica particolare attenzione. Tarrête cita diversi passi de Les Tragiques, dal libro quarto in particolare, per mostrare come d'Aubigné riprenda argomentazioni tertullianee e patristiche, nonché altre utilizzate da Simon Goulart nell'Histoire des Martyrs e nella Briefve Remonstrance, mutuando tra l'altro dal pastore l'impiego del termine stoicheggiante constantia per descrivere una delle virtù necessarie al martire. Gli autori cristiani prediligono infatti parlare di fortitudo o patientia riferendosi all'atteggiamento 
di impassibilità in circostanze avverse proprio del martire, in un certo senso corrispondente all'atarassia stoica. È dunque Goulart, traduttore delle opere complete di Seneca, a introdurre il termine constantia nella temperie culturale che ne consentirà l'adozione da parte di d'Aubigné. Lo studioso definisce in questi termini la posizione di d'Aubigné: «[...] il est à la fois l'héritier du néo-stoïcisme chrétien de Simon Goulart, et le contemporain des réactions anti-stoïciennes de catholiques comme François de Sales, ou François Garasse - premiers jalons sur la route qui mène à la critique du sage chez Malebranche ou Pascal» (p. 96). D’Aubigné si troverebbe dunque sulla soglia di quel divorzio tra morale eroica e morale cristiana che porterà all'anti-stoicismo del secolo successivo. Tarrête mostra infine come il legame tra stoicismo e morale cristiana si approfondisca e arricchisca di nuovi punti di contatto nel frangente delle guerre di religione, allorché il martire, cattolico come ugonotto, si trova non soltanto a dover patire per la propria fede, ma anche per difendere libertà e indipendenza della confessione cui aderisce (come gli antichi difendevano libertà e indipendenza della patria a costo della vita). 